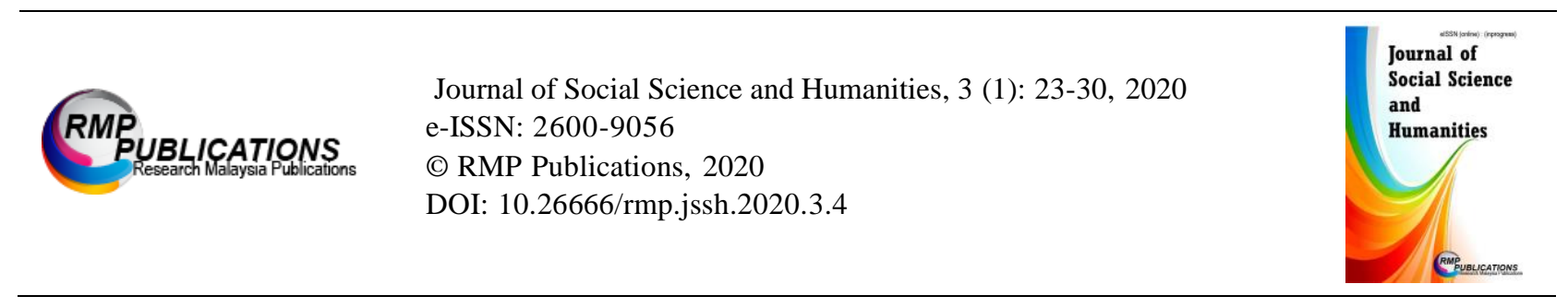

\title{
Should Human Resources Consider Outsourcing Human Resource Development Competencies Based on Past Performance?
}

\author{
Dr. Bob Barrett, Jr. \\ School of Business, American Pubic University, Charles Town, United States
}

\begin{abstract}
Historically, the role and function of Human Resource Management (HRM) professionals has focused on the internal management of employees in their workforce from the point of recruitment to hiring and eventual placement of qualified personnel. However, with the onset of multiple technological advancements, as well as economic, political, cultural, and managerial trends changing and impact every organization's workforce - today's HRM professionals have to be more versed and specialized to deal with not only internal placement of employees, but sometimes have to deal with the outsourcing of work functions and assignments in order to best meet the everchanging needs of a global organization. Consequently, organizations in today's global environment demand more return on their investment and have increasingly been outsourcing work to other professions to accomplish their organizational needs and goals, especially some of the functions of the HRM department.
\end{abstract}

\section{Key words: Outsourcing, human capital, human resource management, knowledge management}

\section{INTRODUCTION}

Human Resource Management's role and function in past decades has changed dramatically since the Hawthorne studies with a focus on the management of human resources in organizations, as well as performance and productivity in general. While the works of Peter Senge tried to united the Human Resource Management (HRM) profession with the Human Resource Development (HRD) to show a link between both disciplines in term of learning in the workplace, as Dr. Leonard Nadler founded the HRD discipline to demonstrate a need for organizations to focus on three key areas; namely 1) education; 2) training and development; and 3) career development. [1] Further, Nadler (1984) noted "Education focuses on learning new skills, knowledge, and attitudes that will equip an individual to assume a new job or to do a different task at some predetermined future time." However, he continues and defines training as "learning that is provided in order to improve performance on the present job." [2]

While the literature has grown in both the HRD and HRM genres, the commonality found between the two areas has been lacking, and to a degree many in the HRM profession still believe that the training and development segment for most organizations should reside and be controlled by HRM professionals, despite the growing accounts of literature produced in both the
HRM and HRD genres that support their own disciplinary should be in control and management of both the training components for the workforce. However, this may not be over the publications of studies, noted observations/experiences, as well as case studies produced on this specific topic, but some have argued that there may be a growing support by writers and practitioners in today's workforce that have observed a deficiency in the area of proper education and training in today's workplace. In a survey done by Adecco Staffing USA, they found that

44 percent of executives said a lack of soft skills was the biggest proficiency gap they saw in the U.S. workforce. And in a report from the International Association of Administrative Professionals, OfficeTeam and HR.com, 67 percent of HR managers said they'd hire a candidate with strong soft skills even if his or her technical abilities were lacking, while just 9 percent would hire someone with strong technical credentials but weak soft skills. [3]

Nonetheless, many have argued that some of the auxiliary functions of the HRM profession could and should be outsourced, especially in the area of the HRD taskings, to other resources to better enable more time and resources for the HRM professionals to properly manage a workforce which is constantly changed due to turbulent economic challenges and issues, as well as realizing that many organizations have to compete more for qualified workers while many of their competitors

Corresponding Author: Dr. Bob Barrett, Professor, School of Business, 1111 West George Street, Charles Town, West Virginia, 25414, United States of America. Contact email: docjob00@msn.com 
are rushing to engage any available qualified workers due to the shrinking workforce in the United States.

\section{Human Resource Development and the Workplace}

While it has been argued that the area of training and development has changed over the years, it should be noted that the interest in training development help to bring forth a new disciplinary area and business known as Human Resource Development (HRD). Also, training and development has enabled more efficiently with the emergence of the HRD profession with a full focus on three key areas of: 1) training and development; 2) education; and 3) career development. Heathfield [4] described HRD "as the framework for helping employees develops their personal and organizational skills, knowledge and abilities". Thus, it should be noted that field of HRD has not always been accepted by all members of business, especially in the field of Human Resource Management (HRM). Traditionally, training development has been a component of HRM for the past several decades. However, with the emergence of the HRD discipline, more specific literature has been introduced from this area by practitioners with a keen expertise and training in the areas of education, train development, and career development. However, all these areas are important in today's workplace? Basically, most traditional managers and supervisors have focused on training and development in the area of improving employee performance skills, but studies have shown that there is still a need for education and career development. Francis and Auter (2017) noted that "While 96\% of chief academic officers of colleges and universities believe that their institutions are very or somewhat effective at preparing students for the workforce, only $11 \%$ of business leaders strongly agree." (para. 3 ). This reflects a big divide between the perspectives of educational institutions and the workforce. However, a larger question may be needed to be examined in terms of whether these two vastly different organizations share the same definitions and understanding as to what is education versus training in theory and practice? [5]

Training and development is used for the reinforcement of current skills and knowledge, but education is the teaching of new skills and content knowledge for the adult learner in the workplace. For example, if a company were to switch their current computer hardware or software programs used in the workplace, there would be a need for training and development instead of education, because employees would have already had a basic set of skills for this type of technology. However, if there were a new type of technology introduced into the workplace that was completely different from the current technology and requiring additional or completely new approaches to technology use, then there would be a need for to educate their workforce with use of these this new technology and/or skills sets in order for the employees to master this new technology to be used with their new job assignments and taskings. Consequently, underlying the determination of the organization's workforce needs or wants, there is still somewhat of a struggle between the HR and training units of some organizations. In particular, in some of the larger organizations, there may both an HRD and HRM set of professionals and/or separate departments, which may either work together in harmony or be at a chaotic state, depending on the organization's structure, culture, and communication/managerial skills sets associated with these professionals. While these two disciplines have been engaged with a disconnect over the past years, now it is even more critical than ever before for them to recognize their own separate, but equally important strengths that can be brought to the table, rather than looking at the weaknesses of each other. One of the current arguments over the years between HRM and HRD is centered on the premise of "who should be in charge?" In theory, this may depend on how the newer component, HRD, may be perceived by the powers either in leadership or HRM. In any event, if they can be brought together or work independent, but yet collaboratively at times, this can be both beneficial for each other and the workforce. Thus, the focus on the potential opportunities that each of them can complement each other, rather than working as two different entities could potentially help to remove any discussion of outsourcing to another third party to manage and deliver needed service of the training and development core competencies in an organization. Nonetheless, one of the key reasons why many organizations have considered or have taken action to outsource their training and development or to terminate current training and development activities may be due to the rising cost of this type of activity in the workplace. [6] Basically, the return on investment is a critical issue in today's workplace; however, it should be noted that how one perceives a return on investment with one organization may vary from one organization to another. Furthermore, it should be noted that the leadership, as well as the HRM and HRD department members, should be working towards increasing the value of their human capital by investing more training dollars, rather than diminishing the budgets as a result. Along the same lines, this paper will focus on the perceived return on investment by some organizations and how they can justify the spending of their budget nor to achieve but was an increase in human performance, as well as showing value to their human capital. [7] 
According to the" 2018 State of the Industry" report, which is supplement to previous studies sponsored by the American Management Association International and LinkedIn Learning, they collected data from 399 diverse organizations with a focus on their learning programs. It should be noted that this is the sixth year that they have conducted this data collection and found that there has been an increasing level of expenditures given to direct learning, even though in previous decades training budgets in many organizations were either drastically reduced or eliminated. They found that "Organizations spent \$1,296 per employee on learning in 2017 . This represents a 1.7 percent increase from 2016, when the average spend per employee was $\$ 1,273$. The number of learning hours per employee remained healthy as well; it was 34.1 hours (slightly more than four eighthour workdays) in 2017, which was the same as 2016" [8] Nonetheless, whether some organizations report an increase in learning costs and/or return on their investments, there is still a growing number of organizations over the past decade or two which have outsourced their training component to other service providers/trainers. In the following section, we will examine what is meant by outsourcing and examine a few of the outsourced HR functions and tasks in the area of training and development.

\section{The Choice of Outsourcing Services - Decision or Dilemma?}

According to mbasKooL.com (2019), they defined HR outsource as the "process in which the human resource activities of an organization are outsourced so as to focus on the organization`s core competencies. [9] Before we can focus on just one key area, namely training, let us examines the types of common outsourced HR functions/activities which have been turned over by some organizations. The following are a few of these functions/services sent out to external HR outsourcing organizations.

- Recruiting, training, and development

- Overseeing organizational structure and staffing requirements

- Tracking department objectives, goals, and strategies

- Employee orientation programs [10]

The key underlying question for outsources lies with the perceived and realized costs for such activities to external sources in which the contracting organization view this as a costsaving measures, as well as a potential manpower reduction movement in some cases. Reddy (2019), provided the following lists of pros or "merits" for HR outsourcing:

1. Cost savings

2. Efficiency
3. Define Impact

4. HR Technology Investment Avoidance

5. Strategy Delivery

6. Quality Improvement

7. Risk Management

8. Knowledge Base Increase

9. Employer Branding Awareness

10. Increase in Productivity and Customer

11. Regaining Primary Focus [11]

Equally important, Reddy (2019) provided several cons or "demerits for such HR outsourcing, as noted below.

1. Morale

2. Lack of In-House Expertise

3. Confidentiality

4. Loss of Human Factor [12]

In order to gain a better insight reason for HR to outsource, other than just the training element, we will examine a key HR benefit area that some, but sometimes comprised of a limited number of employees, will utilize as part of their employee benefits. For example, many organizations have experienced problems with Employee Assistant Programs (EAPs), which are designed to help employees through various work-life conflicts, but if not managed and monitored properly, they can create chaotic and conflict problems both in the employee's work and personal life settings. However, the underlying question here is simple why would any HR department outsource such a benefit area? Simply put - the lack of professionals in the current organization having specialized education and training to deliver assistance in this "well-defined" benefit area, as well as a certain level of mistrust that may be present between the human capital in the workplace and HR. For purposes of this chapter, the topic of trust versus mistrust of leading HR issue/challenge will be held for a later discussion. [13] Therefore, one needs to examine how some benefits are outsourced as part of an outsourcing process for realistic and practical purposes; thus, an organization needs to monitor such outsourcing to determine if it is worth the perceived and expected savings to the organization in terms of monetary costs, time management, and manpower costs. However, some of these outsourced HR tasks, such as benefits and/or training and development have gained an "air of discontent, distrustfulness, and/or fluctuating costs" associated with such outsourcing as noted in the media.

According to a blog produced by the Business Group [14], they found that

Employee Assistance Programs (EAPs) are offered at 97\% of large employers. However, studies show that only $5 \%$ of employees use them annually; for National Business Group on Health members, the EAP utilization rate is $8 \%$. EAPs are work-based intervention programs designed to identify and assist employees in resolving personal or work-related issues that could adversely affect their productivity. EAPs offer many benefits. For employers, they can help reduce overall health care claims, workers' compensation and disability costs. For employees, EAPs can reduce the impact of mental health disorders, workplace stress and other work/life issues. Studies show that EAPs produce an ROI of $\$ 3-\$ 10$ for every $\$ 1$ invested. [15-19] 
Some have speculated that employees tend not to trust "outsourced" HR resources due to their lack of "personal" knowledge or acquaintance with these other individuals.[20]

As noted earlier in this chapter, there has been a disconnect between the HRM and HRD components of an organization. However, this may be explained due to the leadership or management of members of each of these departments or components and an organization which could be the result of a lack of understanding of each other or the style of leadership exerted in the organization over its various human capital. For the purposes of this paper, the use of human capital will be used in lieu of employees. [21] Consequently, this paper article will examine how earlier struggles between the HRM and HRD profession have not only divided them at times, but can also work as a trigger for a potential series of events to benefit both of them mutually exclusively without outsourcing to a third party, but rather to engage HRD's expertise and subject-matter experts to help realign the training and development of an organization's core competencies and build its organizational learning potential. In this next section, a discussion will be held on the shrinking workforce and the competition among employers in finding and retaining qualified human capital for their current and future positions. It should be noted that due to the increase of baby boomers retiring, the competition among employers has increased. On the other hand, it should be noted as more businesses are appearing on the horizon, the human capital is migrating to the best paint employers in terms of salaries and benefits. Consequently, it should be noted that also the opportunities given to potential candidates are important, such as training development, career development, and overall professional development in the workplace. However, not all employers feel that career development is important - if there is a chance that the employee will move onward to another organization. [22] The traditional employee is no longer in the workforce, however, a new type of employee such as noted by key authors in the literature has now populated the marketplace. According to a Burson report in 2017, they discovered that

... only 42 percent of Americans with a high school education or less say they have the right skills to succeed in the 21 st century, while 71 percent with a college education or more say they do. When asked what emotion best describes their feeling about the future of the U.S. economy, Americans with high school or less are 25 percent less likely to say they are optimistic than those with a college education or more. And they are 50 percent more likely to feel scared about the future of the U.S. economy than those with a college education or more. [23]

Considering this report in terms of the lack of proper training and education of the American workforce, can American business truly trust others with preparing their current and future workforce? Or the larger question may be whether or not if companies can fully trust others in terms of outsourcing this important HR training benefit or not? In order to better understand this problem contextually, one needs to look at the reasons for the shrinking workforce and the need for a re-examination of the current and future training needs of today's current and future workforce.

\section{The Shrinking Workforce and Competitive Employers}

In retrospect to the challenges and issues of a shrinking workforce and the associated growing training and development costs, which may not be properly managed in terms of potential return-on-investment, organizations today need to reevaluate their core competencies and properly alignment of department taskings, rather than re-investing them when they do not fit the total "expected" organizational picture. The key focus here should be on what are the core competencies, as well as the goals and objectives, needs by organization in today's marketplace. Who determines these core competencies? Is it the HRM or the HRD departments? Or does the leadership and/or managers of the organization determine what are the core competencies after determining first the goals and objectives of the organization as a means of control and managerial style? However, for the purposes of this discussion, we will focus on core competencies in the area of training and development needed for organizations to focus on the improvement of the overall performance of their human capital

One of the key problems faced in the 1990s by Corporate America has been in the area of reengineering, in which a number of organizations failed in this new approach to leadership and managerial style. Champy and Hammer (1993) noted in the "Reengineering the Corporation" that one of the key downfalls of this movement was the "lack of corporate or upper-management buy-in" and, in turn, this resulted in the downfall of many attempts by various organizational stakeholders trying to reengineer various segments of the entity's overall structure, culture, and workforce. [24] Consequently, if we look at the management of the training and development management in organizations, whether they specifically have organizational learning or declare themselves to be a learning organization, one can see that there might be an element of disconnect between upper-management's "buy in" and support of this function of the organization which may weaken the HRM's ability to properly fund and manage in this area. As a result, this may be one of the key weaknesses in any organization in which there is a lack of "buy-in" from upper-management in which HR professionals may be struggling at times to use what they have in terms of personnel, equipment, and technology to try to improve the performance, abilities, and skills sets of its personnel, but yet could be lacking in the proper assessment of training needs and overall development 
of "quality training programs" to help support their workforce. Thus, this is one of the key arguments used in industry today to support the need for "outsourcing" of this particular area of HR. Nonetheless, in order to better understand the mismatch or conflict between HR, one might need to look at some of the internal stakeholders, such as the HRM and HRD professionals and/or respective departmental controls.

\section{Human Resource Management and Human Resource Development: The Mystery of the Two Disciplines}

While some experts and leading authors in the genres of HRM and HRD have argued that there is a need for both disciplinary areas to merge, they both seem to be polarized and want to declare their own independency from each other. Nonetheless, this disciplinary divide as evidence in today's marketplace has done relatively nothing to advance their cause, but rather it has driven a wedge even further between both groups to perhaps cause even more speculation as to why the use of outsourcing for the training and development needs of organizations should be utilized, rather than the internal department members historically entrusted with this key organizational need for the workforce. Consequently, several writers of the HRD literature have argued that this divide could be lessen or removed, if there were a new "relationship" developed over time in terms of a stronger bonding effort between both HRM and HRD in terms of relinquishing the training and development element of today's organization as a result of past experiences. Furthermore, some members of these groups are trying to move forward [25] as a new attempt to create their own chapter in both knowledge management and develop yet a new type or learning organization in which both departments could work as cocreators and partners in designing and developing, implementing, and evaluating more effective training programs that help not only the workforce, achieve better overall workforce performance and productivity, but also serve as best practices for other organizations, which may be facing the same type of internal and external struggles, challenges, and issues affecting their workforce in the area of training and development as the beginning states of working towards the creating and nurturing of their own learning organization, as well as creating a new area focused on knowledge management. Thus, this helps to redirect the focus here on the struggles, challenges, and issues faced not only by professionals in the HRM and HRD areas, but highlight the needs of today's organizations in moving forward with ever-changing technological growth and competition. In particular, many entities have been struggling in finding qualified workers who may also need specific or additional "training needs" in order to help the organization to achieve its current and future organizational goals while competing in an ever-changing marketplace. The next section will examine some of these current struggles and issues that organizations may be facing in the area of training and development.

\section{Current Struggles and Issues with a Shrinking Workforce}

While the internal elements and factors, as well as both internal and external stakeholders may control some areas of the workforce and overall workplace, the external counterparts also play a critical role in how HRM and HRD professionals interact, operate, and evaluate elements in their daily taskings and assignments. The use of stakeholder theory can help to understand whether or not internal or external stakeholders can help with the maintenance of training in the workplace or perhaps assist with the outsource of training with specific/matched subject-matter experts, training consultants, trainers or training organizations. [26][27][28] Contextually, this theory can help one to understand how internal and external stakeholders connected to both the HRM and HRD segments of an organization can help to management key areas of their departmental endeavors or understand the need to outsource one or more of these functions to appropriate providers. While there may be a variety of theories that could be used in literary writings when discussing or debating certain case studies and actual workplace dilemmas or situations, the overall influence of the stakeholders has been historically critical, as well as the impact of its associated gatekeepers who have helped to control the various functions of both organizational and departmental duties. Such control of information and the follow of certain types of communication or date or information has been discussed in the context of "dominant logic" in terms of its impact, role, and function in the workplace.

Prahalad and Bettis (1986) discussed the term "dominant logic" as the ability of upper management or authority in the control of the flow of information in and out of an organization.[29] One of the key problems with a workforce, especially with a shrinking workforce, is the control of data and how the data is used in various organizational decisions and actions, such as performance evaluations, training and development, and workforce prediction and forecasting. Therefore, we need to look at current struggles and issues faced by members of management and organization in obtaining and retaining the best qualified workers in order to meet organizational needs and goals. Thus, this helps one to consider whether or not perhaps there should be a closer bonding of the HRM and HRD components in an organization in order to help an organization to both learn and grow. As discussed earlier, the term organizational learning and learning organization have been one of the most misused and misunderstood terms in the past decade in both 
the literature and in the workplace. The question is why they been misunderstood and misused? For example, many organizations like to acquire new buzzwords or trends that others have used or the have read about in the trade press. However, does this help them to better understand the use of such terms or does it perpetuate misunderstanding in the workplace and perhaps misunderstanding of the human capital and their learning and training needs? For the purposes of this discussion, we will examine what are these two terms after a quick discussion of why the HRM and HRD components should be brought together under one umbrella department or perhaps the training and development component or should they be housed separately in a new department, formerly known as training and development. The following section will look at either the combined efforts of these two functional areas or the separation of them.

\section{CONCLUSION}

While there has been competition between the traditional HRM department and the newly formed HRD, combined in most businesses, some have argued that a marriage or merger between the two departments or components could be more beneficial to the overall organization, rather than a separation of the two. [30] It should be noted, whether the training and and development component is housed in one or two departmentsor outsourced to another entity, the need for quality training development, education, career development, and/or professional development is equally needed by many members of an organization's workforce. For example, let us look at three possible scenarios here. First, what if the HRM department took complete control of the training and development component, but they soon realized that they were not fully equipped with the personnel who could develop and design, as well as implement quality training for the workforce? Second, what if the training and development segment were given to professionals in an HRD department, along with specialized subject-matter experts equipped with experience and education and instructional systems design (ISD), could this be a viable solution? Finally, what if the training and development segment was outsourced to a thirdparty provider, would this make any difference in terms of how the training was developed and implemented, as well as being developed to match the needs of the organizational culture, workforce performance needs, as well as the organizational goals? Consequently, this raises several questions to contemplate for further exploration and examination. These are areas that the researcher seeks to obtain deeper and fuller answers to these questions to find out if the marriage of the fields of HRM and HRD can work closer together and help work more towards better understanding of today's human capital (employees) and help in the areas of training, motivation, and performance.

- First, what if the HRM department took complete control of the training and development component, but soon realized that they were not fully equipped with the personnel they could develop and design, as well as implement quality training for the workforce?

- Second, what is the training and development component were given to professionals in a HRD department with specialized subject-matter experts equipped with experience and education and instructional systems design (ISD)?

- Finally, what is the training and development component were outsourced to a third party, with this make any difference in terms of how the training was developed and implemented, as well as perceived by the workforce?

\section{REFERENCES}

1. Senge, P. M. (1990). Peter Senge and the learning organization. Infed. Retrieved from http://infed.org/mobi/peter-senge-and-the-learningorganization/

2. Nadler, L. (1984). The Handbook of Human Resource Development. New York: John Wiley \& Sons. Nonaka, I. (1991). "The Knowledge-Creating Company," Harvard Business Review.

3. Adecco (2013). Lack of Soft Skills Negatively Impacts Today's U.S. Workforce. Retrieved from https://www.adeccousa.com/about-adeccostaffing/newsroom/press-releases/lack-of-softskills-2013//.

4. Heathfield, S.M. (2010) "What is human resource development (HRD)" About.com humanresources.about.com/od/glossaryh/f/hr_devel opment.htm.

5. Francis, J., Auter, Z. (2017). 3 Ways to Realign Higher Education With Today's Workforce. Retrieved from https://news.gallup.com/opinion/gallup/212522/wa ys-realign-higher-education-today-workforce.aspx.

6. ERC (2016). 7 Rising Trends in Employee Training and Development in 2016. HR Insights Blog. Retrieved

from https://www.yourerc.com/blog/post/7-rising-trendsin-employee-training-and-development-in-2016.

7. Forbes (2017). The Value Of Human Capital: Measuring Your Most Important Assets. Retrieved from https://www.forbes.com/sites/adp/2017/11/15/thevalue-of-human-capital-measuring-your-mostimportant-assets/\#5364bf9a5a32. 
8. Association for Talent Development (ATD) (2018). 2018 State of the Industry. Retrieved from https://www.td.org/researchreports/2018-state-of-the-industry.

9. mbasKooL.com (2019). HR Outsourcing. Retrieved from https://www.mbaskool.com/businessconcepts/human-resources-hrterms/7268-hr-outsourcing.html.

10. mbasKooL.com (2019). HR Outsourcing. Retrieved from https://www.mbaskool.com/businessconcepts/human-resources-hrterms/7268-hr-outsourcing.html.

11. Reddy, C. (2019). Top 15 Pros and Cons of Outsourcing HR Services. Retrieved from https://content.wisestep.com/toppros-cons-outsourcing-hr-services/.

12. Reddy, C. (2019). Top 15 Pros and Cons of Outsourcing HR Services. Retrieved from https://content.wisestep.com/toppros-cons-outsourcing-hr-services/.

13. O'Hara, C. (June 27, 2014). Proven Ways to Earn Your Employees' Trust. Harvard Business Review. Retrieved from https://hbr.org/2014/06/provenways-to-earn-your-employees-trust.

14. Business Group Blog (2019). National Business Group on Health. Increasing Employee Assistance Program Effectiveness and Utilization: New Approaches and Emerging Trends. Retrieved from https://blog.businessgrouphealth.org/blo g/eap-effectiveness/.

15. National Business Group on Health and Fidelity Investments. Employer investments in improving employee health: results from the fifth annual National Business Group on Health/Fidelity Investments Benefits Consulting survey. https://www.businessgrouphealth.org/pu b/bdf7866d-782b-cb6e-2763-

182a7a686dd5. Published 2014. Accessed May 20, 2014.

16. National Business Group on Health. Global employee assistance programs. Survey Report. http://www.businessgrouphealth.org/pub /0ffad40b-782b-cb6e-2763-

6bcabe78a271. Published 2014. Accessed August 25, 2014. https://www.businessgrouphealth.org/pu b/befd14fa-782b-cb6e-2763-

cfc53306fcad. Published 2013. Accessed May 20, 2014. Blum T, Roman P. CostEffectiveness and Preventive
Implications of Employee Assistance Programs. Rockville, MD: U.S. Department of Health and Human Services; 1995.

17. Collins, K.M. (1998). Cost/benefit analysis shows EAP's value to employer. EPA Exchange, 28 (12):16-20.

18. Merrick, E.S., Volpe-Vartania, J., Horgan, C.M., et al. (2007). Revisiting employee assistance programs and substance use problems in the workplace: key issues and research agenda. Psychiatric Services;58(10):1262-1264.

19. Attridge, M., Amaral, T., Bjornson, T., et al. (2009) EAP effectiveness and ROI. EASNA Research Notes. $\quad$ http://www.easna.org/wpcontent/uploads/2010/08/EASNA-Research-NotesNo-3-ROI-NOV12010.pdf. Accessed January 8, 2015.

20. Essays, UK. (November 2018). The advantages and disadvantages of outsourcing. Retrieved from https://www.ukessays.com/essays/informationtechnology/the-advantages-and-disadvantages-ofoutsourcing-information-technologyessay.php?vref $=1$

21. SHRM (2019). 2019 Deloitte Global Human Capital Trends and Their Impact on Your Organization. Webcast, retrieved from https://www.shrm.org/LearningAndCareer/learning / webcasts/Pages/0619hrfuture.aspx.

22. Moran, Gwen (2017). How To help build employees' career paths so they don't quit: Budgets, hiring freezes, and lack of career pathways can all inhibit employee development. Here's the workaround. Fast Company (2017). Retrieved from https://www.fastcompany.com/40490723/how-tohelp-build-employees-career-paths-so-they-dontquit/

23. Carufel, R. (2017, July 24). New Burson report: How education impacts Americans' future worldviews. Agility PR Reports. Retrieved from https://www.agilitypr.com/pr-news/publicrelations/new-burson-report-education-impactsamericans-future-worldviews/.

24. Hammer, M., Champy, J., (1993). Reengineering the corporation. Harper Business, New York, NY.

25. Rosseau, D.M. (2015). Developing an evidencebased HRM through the conscientious reliance on evidence, sound decisions, process, and stakeholders perspectives. The rise of HR: Wisdom from 73 thought leaderships. Retrieved from https://www.hrci.org/docs/defaultsource/ebook/hrci_theriseofhr_epub_r.epub.

26. Agle, B.R., Mitchell, R.K., Wood, D.J. (1997). Toward a theory of stakeholder identification and salience: Defining the principle of who and what really counts. Academy of Management Review, 22(4), 853-886. Cited by 9623 .

27. Freeman, R.E. (2010). Strategic management: A stakeholder approach. Cambridge University Press. Cited by 24540 . 
Barrett/ Journal of Social Sciences and Humanities, 3(1) 2020, Pages: 23-30

28. Bonnafous-Boucher, M., \& Rendtorff, J. D. (2016). Stakeholder theory and ethics. Stakeholder Theory (pp. 67-78). Springer International Publishing.

29. Prahalad, C. K.; Bettis, Richard A. (1986). "The dominant logic: A new linkage between diversity and performance." Strategic Management Journal 7(6): 485-501. Retrieved from https://deepblue.lib.umich.edu/handle/2027.42/106 722/

30. SHRM (2019). 2019 Deloitte Global Human Capital Trends and Their Impact on Your Organization. Webcast, retrieved from https://www.shrm.org/LearningAndCareer/learning / webcasts/Pages/0619hrfuture.aspx. 
